\title{
PERUBAHAN PENGGUNAAN LAHAN DAN POTENSI PERLUASAN LAHAN UNTUK SAWAH DI KABUPATEN CIANJUR
}

\section{Land Use Change and Land Expansion Potency for Paddy Field in Cianjur Regency}

 \\ 1) Alumni Program Studi Perencanaan Wilayah, Sekolah Pascasarjana IPB, Jl. Meranti Kampus IPB Darmaga, \\ Bogor, 16680 \\ 2) Departemen Ilmu Tanah dan Sumberdaya Lahan, Fakultas Pertanian IPB, Jl. Meranti Kampus IPB Dramaga, \\ Bogor 16680
}

\begin{abstract}
Population growth, increasing income, and the rapid economic development create complexity of land issues. Land has a central role in food production, however demand for land increased significantly to meet the needs of the population. Cianjur Regency is one of regencies in the southern part of West Java Province with the largest paddy field area. However, paddy field conversion into non agricultural land or another agricultural land resulted in the decrease of paddy field area. Therefore, in the context of maintaining the availability of rice in Cianjur Regency, this study aimed to: (1) analyze the patterns of land use/land cover, (2) evaluate land suitability for paddy field, and (3) analyze the potency of land for paddy field expansion. Land use change was identified using Landsat imagery of 2000 and 2015 by using fusion techniques. Land suitability for paddy field was analyzed using limiting factor method. Potential for paddy field expansion was analyzed according to land suitability and agricultural land allocation in official regional land use plan map ("RTRW"). The results showed that in the period of 2000 to 2015, most of paddy field were converted into settlements. Land suitability classes for paddy field in Cianjur Regency were not suitable (N) (61.19\%), suitable (S2) (9.53\%), and marginally suitable (S3)(29.28\%). Cianjur Regency still has the potency of land to be used for paddy field expansion of 148,980 ha.
\end{abstract}

Keywords: Land use change, potential area for paddy field priority, land suitability for paddy field

\section{ABSTRAK}

Pertumbuhan penduduk, peningkatan pendapatan, dan pesatnya pembangunan menjadikan permasalahan penggunaan lahan semakin kompleks. Lahan berperan sebagai penyedia pangan, namun di sisi lain permintaan lahan di luar sektor pertanian terus meningkat secara signifikan untuk memenuhi kebutuhan penduduk. Kabupaten Cianjur merupakan kabupaten dengan luas sawah terbesar pertama di bagian selatan Provinsi Jawa Barat. Namun, konversi lahan sawah menjadi lahan pertanian lain atau lahan non-pertanian menyebabkan penurunan luas baku sawah. Penelitian yang bertujuan untuk: (1) menganalisis pola perubahan penggunaan dan penutupan lahan, (2) mengevaluasi kesesuaian lahan untuk sawah, dan (3) menganalisis potensi perluasan penggunaan lahan untuk sawah. Pola perubahan penggunaan dan penutupan lahan diidentifikasi menggunakan citra Landsat tahun perekaman 2000 dan 2015 dengan teknik fusi citra. Kesesuaian lahan untuk sawah dianalisis menggunakan metoda faktor pembatas minimum. Potensi perluasan lahan untuk sawah mengacu pada kesesuaian lahan dan alokasi lahan pada Rencana Tata Ruang Wilayah (RTRW). Hasil penelitian menunjukkan bahwa pada periode analisis, lahan sawah paling banyak terkonversi menjadi pemukiman. Lahan di Kabupaten Cianjur memiliki tingkat kesesuaian lahan untuk sawah sesuai (S2) (9.53\%), sesuai marjinal (S3) (29.28\%) dan tidak sesuai (N) (61.19\%). Saat ini, masih tersedia potensi lahan untuk perluasan sawah di Kabupaten Cianjur seluas 148,980 ha.

Kata kunci: Perubahan penggunaan lahan, prioritas potensi sawah, kesesuaian lahan untuk sawah

\section{PENDAHULUAN}

Lahan sawah memegang peranan penting dalam penyediaan kebutuhan beras. Beras merupakan makanan pokok bagi lebih dari setengah populasi dunia sehingga sangat penting untuk ketahanan pangan (Belesky, 2014; Cornish et al., 2015; Qiu et al., 2015; Yang and Zhang, 2014). Produksi beras di Indonesia 94\% dihasilkan dari usahatani padi sawah, sisanya dihasilkan dari usahatani padi lahan kering. Dengan luas wilayah hanya $7 \%$ daratan Indonesia, Pulau Jawa masih menjadi penyumbang produksi beras terbesar, mencapai $53 \%$ dari total produksi beras nasional (Widiatmaka et al., 2014).
Provinsi Jawa Barat sebagai salah satu lumbung padi nasional selama 30 tahun terakhir, rata-rata telah menyumbang sekitar $22 \%$ produksi padi nasional dan lebih dari $95 \%$ produksi padi tersebut dihasilkan dari lahan sawah, sisanya dihasilkan dari lahan kering (Balitbang Kementan, 2011). Kabupaten Cianjur merupakan salah satu lumbung padi di Jawa Barat yang perlu dipertahankan mengingat sebanyak 882,662 ton padi dihasilkan dari wilayah ini (BPS Provinsi Jawa Barat, 2014). Penduduk Kabupaten Cianjur yang sebagian besar bekerja sebagai petani menjadikan sektor pertanian sebagai kontributor utama untuk Produk Domestik Regional Bruto (PDRB). 
Pada tahun 2013 sektor ini menyumbang 37\% (BPS Kabupaten Cianjur, 2014).

Pertambahan penduduk, peningkatan pendapatan, dan pesatnya pembangunan menjadikan permasalahan penggunaan lahan semakin kompleks. Persaingan penggunaan lahan yang terjadi secara riil di lapang pada akhirnya akan selalu dimenangkan oleh kegiatan nonpertanian karena nilai sewa lahan (land rent)-nya lebih menguntungkan secara ekonomi. Penggunaan lahan pertanian yang mempunyai potensi paling besar untuk terkonversi adalah lahan sawah. Kondisi tersebut terkait dengan aspek spasial lahan sawah, dimana: (1) kebutuhan lahan untuk kegiatan non-pertanian lebih menguntungkan, terutama pada lahan yang datar dimana sawah pada umumnya berada, (2) infrastruktur seperti jalan lebih tersedia di daerah persawahan, (3) daerah persawahan pada umumnya lebih mendekati wilayah konsumen yang relatif padat penduduk dibandingkan lahan kering yang sebagian besar terdapat di daerah bergelombang, perbukitan dan pegunungan.

Data Sensus Pertanian (BPS Kabupaten Cianjur, 2003) menunjukkan bahwa selama tahun 2000-2003 di Kabupaten Cianjur terjadi konversi sawah menjadi lahan non pertanian sebesar $0.34 \%$ per tahun. Sejak tahun 2010, laju konversi meningkat menjadi $0.63 \%$ per tahun (PUSDATIN KEMENTAN, 2014). Sementara itu, perkembangan penduduk Kabupaten Cianjur memperlihatkan pola berlipat dua setiap 40 tahunan, yang tentunya terus mengancam keberadaan lahan sawah dan meningkatkan permintaan terhadap beras maupun berbagai produk serta sumberdaya lahan

Upaya pemerintah untuk mencegah konversi lahan pertanian telah dilakukan melalui regulasi, antara lain dengan diundangkannya UU No. 41 Tahun 2009 tentang Perlindungan Lahan Pertanian Pangan Berkelanjutan (LP2B). Untuk mendukung upaya pemerintah tersebut, penelitian ini bertujuan untuk: (1) menganalisis perubahan penggunaan lahan Kabupaten Cianjur dalam dua titik tahun, yaitu 2000 dan 2015, (2) menganalisis kesesuaian lahan untuk sawah di Kabupaten Cianjur, dan (3) menganalisis lahan bukan sawah yang berpotensi untuk dijadikan sawah.

\section{BAHAN DAN METODE}

Penelitian dilaksanakan pada bulan Desember 2014 sampai Desember 2015 di Kabupaten Cianjur. Secara geografis, wilayah ini terletak pada $106^{\circ} 42^{\prime}-107^{\circ} 25^{\prime}$ BT dan $6^{\circ} 21^{\prime}-7^{\circ} 25^{\prime}$ LS. Kabupaten Cianjur terdiri dari 32 kecamatan dan 347 desa/kelurahan yang terbagi dalam 3 wilayah pembangunan (WP), yaitu WP Cianjur Utara, WP Cianjur Tengah, dan WP Cianjur Selatan. WP Cianjur Utara merupakan wilayah dengan konsentrasi penduduk dan kegiatan ekonomi tinggi, sehingga dapat mendorong pengembangan bagian wilayah lainnya. Sementara ini, WP Cianjur wilayah tengah dan selatan merupakan wilayah yang tertinggal dan sebagian kecamatan merupakan wilayah yang sulit dijangkau (Cahyaningrum et al., 2014; Suhaema et al., 2014).

\section{Data dan Sumber Data}

Data yang digunakan dalam penelitian ini terdiri dari data primer dan data sekunder. Data primer yang digunakan adalah data citra dan data analisis tanah di laboratorium. Citra satelit Landsat tahun perekaman 2000 dan 2015 diperoleh dari situs penyedia data citra satelit (http://earthexplorer.usgs.gov/). Data sifat kimia tanah yang digunakan merupakan hasil analisis laboratorium terhadap sampel tanah yang diambil dari lapang. Data sekunder yang digunakan berupa peta Rupa Bumi Indonesia (RBI) skala 1:25,000 dari Badan Informasi Geospasial (BIG), peta satuan lahan dari Balai Besar Penelitian dan Pengembangan Sumberdaya Lahan Pertanian (BBSDLP), peta administrasi dari Badan Perencanaan Pembangunan Daerah (BAPPEDA) Kabupaten Cianjur, peta lereng dan peta elevasi yang dibuat dari Digital Elevation Model Shuttle Radar Topography Mission (DEM SRTM). Data kelengkapan sarana pertanian diperoleh dengan melakukan penelusuran ke instansi pemilik data, wawancara di daerah penelitian, penelusuran situs internet, penelitian terdahulu dan studi pustaka.

\section{Analisis Data}

\section{Analisis Spasial Perubahan Penggunaan Lahan}

Penggunaan lahan tahun 2000 dan tahun 2015 diinterpretasi secara visual dari citra Landsat. Citra landsat banyak digunakan sebagai data primer untuk analisis perubahan penggunaan lahan (Borrelli et al., 2014; Kim et al., 2014; Kolios and Stylios, 2013). Interpretasi citra merupakan perbuatan mengkaji citra dengan maksud untuk mengidentifikasi obyek dan menilai arti pentingnya obyek tersebut. Sebelum dilakukan interpretasi, terlebih dahulu dilakukan fusi citra. Fusi citra merupakan prosedur yang digunakan untuk mengintegrasikan data spasial sehingga informasi spasial dan spektral dari setiap data tersebut dapat digabungkan untuk menghasilkan data baru yang lebih baik. Peta penggunaan lahan yang dihasilkan kemudian digunakan untuk menganalisis perubahan penggunaan lahan yang terjadi pada periode tersebut melalui proses overlay.

\section{Pengambilan Sampel Tanah dan Analisis Laboratorium}

Pengambilan contoh tanah dilakukan secara purposive, dimana jumlah contoh tanah disesuaikan dengan keragaman unit lahannya. Satuan peta tanah (SPT) digunakan sebagai dasar dalam pengambilan contoh tanah. Komponen SPT yang digunakan meliputi bahan induk, jenis tanah dan bentuk lahan. Pemilihan lokasi pengeboran tanah di lapang ditentukan dengan pertimbangan, lokasi terpilih mewakili karakteristik unit lahan dan kemudahan aksesibilitas. Pengambilan contoh tanah dilakukan pada kedalaman 0-30 cm. Analisis laboratorium dilakukan di Laboratorium Departemen Ilmu Tanah dan Sumberdaya Lahan, Institut Pertanian Bogor.

Secara keseluruhan, dari 110 contoh tanah yang diambil, 67 contoh tanah dianalisis di laboratorium. Analisis yang dilakukan adalah tekstur (tiga fraksi), $\mathrm{pH} \mathrm{H}_{2} \mathrm{O}$ 1:1, Carbon Organik, Total Nitrogen, $\mathrm{K}_{2} \mathrm{O}, \mathrm{NH}_{4} \mathrm{OAC} \mathrm{pH}$ 7.0 (Ca, Mg, K, Na), kapasitas tukar kation (KTK) dan KB (Kejenuhan Basa), Al dan $\mathrm{H}(\mathrm{N} \mathrm{KCl})$. Hasil lengkap analisis laboratorium telah disajikan pada laporan penelitian Munibah (2015). 


\section{Evaluasi Kesesuaian Lahan Sawah}

Dalam penelitian secara keseluruhan, evaluasi kesesuaian lahan diperlukan sebagai dasar pengalokasian lahan dalam model perubahan penggunaan lahan. Evaluasi dilakukan melalui matching kualitas dan karakteristik lahan dengan persyaratan penggunaan lahan menggunakan pendekatan faktor pembatas, yaitu faktor lahan yang mempunyai pengaruh yang merugikan bagi suatu tipe penggunaan lahan (Hardjowigeno dan Widiatmaka, 2007). Kriteria evaluasi yang digunakan mengacu pada Hardjowigeno dan Widiatmaka (2007) (Tabel 1).

Tabel 1. Kriteria kesesuaian lahan untuk sawah

\begin{tabular}{|c|c|c|c|c|c|}
\hline \multirow{3}{*}{ Karakteristik Lahan } & \multirow{3}{*}{ Simbol } & \multicolumn{4}{|c|}{ Kelas Kesesuaian Lahan } \\
\hline & & $\mathrm{S} 1$ & S2 & S3 & $\mathrm{N}$ \\
\hline & & \multicolumn{4}{|c|}{ Kriteria Karakteristik Lahan Permanen } \\
\hline 1. Ketersediaan air & w & & & & \\
\hline Curah Hujan (mm/thn) & & $>1500$ & $1200-1500$ & $800-1200$ & $<800$ \\
\hline 2. Media Perakaran & $\mathrm{r}$ & & & & \\
\hline Draniase Tanah & & Terhambat & Terhambat & Sedang, baik & $\begin{array}{c}\text { Cepat, } \\
\text { Sangat cepat }\end{array}$ \\
\hline Tekstur & & SCL,SiL, Si, CL & $\mathrm{SL}, \mathrm{L}, \mathrm{SiCL}, \mathrm{C}, \mathrm{SiC}$ & LS, Str C & Kerikil, Pasir \\
\hline Kedalaman Efektif $(\mathrm{cm})$ & & $>50$ & $40-50$ & $25-40$ & $<25$ \\
\hline 3. Tingkat Bahaya Erosi & $\mathrm{e}$ & & & & \\
\hline \multirow[t]{2}{*}{ Lereng $(\%)$} & & $<3$ & $3-8$ & $8-15$ & $>15$ \\
\hline & & \multicolumn{4}{|c|}{ Kriteria Karakteristik Lahan Tidak Permanen } \\
\hline 4. Retensi Hara & f & & & & \\
\hline KTK Tanah & & $\geq$ sedang & Rendah & Sangat Rendah & td \\
\hline Kejenuhan basa (\%) & & $>50$ & $35-50$ & $<35$ & - \\
\hline pH Tanah & & $>5,5-7,0$ & $>7,0-8,0 ; 4,5-5,5$ & $\begin{array}{c}>8,0-8,5 ; 4,0- \\
\quad<4,5\end{array}$ & $>8,5 ;<4,0$ \\
\hline C-organik (\%) & & $>1,5$ & $0,8-1,5$ & $<0,8$ & - \\
\hline 5. Hara Tersedia & $\mathrm{n}$ & & & & \\
\hline TotalN & & $\geq$ sedang & Rendah & Sangat Rendah & - \\
\hline
\end{tabular}

Sumber: Harjdowigeno dan Widiatmaka (2011)

\section{Analisis Prioritas Potensi Lahan untuk Perluasan Sawah}

Potensi lahan untuk perluasan sawah diperoleh dari hasil overlay lahan pertanian non-sawah dan lahan tidak produktif dari peta penggunaan lahan tahun 2015, peta kesesuaian lahan untuk sawah, serta peta Rencana Tata Ruang Wilayah (RTRW). Analisis hanya dilakukan pada bagian wilayah yang dalam RTRW dialokasikan untuk kegiatan pertanian. Tingkat pemrioritasan $(\mathrm{P})$ ditentukan berdasarkan tingkat kesesuaian lahan sawah dan jenis alokasi lahan pada RTRW.

\section{HASIL DAN PEMBAHASAN}

\section{Pola Spasial Perubahan Penggunaan Lahan}

Penggunaan/penutupan lahan di Kabupaten Cianjur tahun 2000 dan 2015 terdiri dari 9 kelas yaitu hutan, kebun/kebun campuran, pemukiman, sawah, ladang, semak belukar/tanah terbuka, danau/situ, sungai dan Taman Bunga Nusantara. Selama periode tersebut, penggunaan/penutupan lahan hutan, ladang, sawah, dan semak belukar mengalami penurunan sedangkan pemukiman dan kebun/kebun campuran mengalami peningkatan. Tubuh air dan Taman Bunga Nusantara (danau/situ dan sungai) tidak mengalami perubahan (Tabel 2).
Tabel 2. Perubahan penggunaan/penutupan lahan di Kabupaten Cianjur tahun 2000-2015

\begin{tabular}{lrrrrrr}
\hline \multirow{2}{*}{ Jenis Penggunaan Lahan } & \multicolumn{2}{c}{ Tahun 2000 } & \multicolumn{2}{c}{ Tahun 2015 } & \multicolumn{3}{c}{ Perubahan 2000-2015 } \\
\cline { 2 - 7 } & \multicolumn{1}{c}{ ha } & \multicolumn{1}{c}{ ha } & \multicolumn{1}{c}{ ha } & $\%$ \\
\hline Danau/Situ & $2.220,0$ & 0,61 & $2.220,0$ & 0,61 & - & - \\
Hutan & $52.798,2$ & 14,59 & $47.223,5$ & 13,05 & $-5.574,7$ & $-1,54$ \\
Kebun/Kebun Campuran & $100.645,0$ & 27,81 & $109.192,5$ & 30,17 & $8.547,4$ & 2,36 \\
Ladang & $52.696,8$ & 14,56 & $48.017,8$ & 13,27 & $-4.679,1$ & $-1,29$ \\
Pemukiman & $18.029,1$ & 4,98 & $25.477,3$ & 7,04 & $7.448,2$ & 2,06 \\
Sawah & $77.576,0$ & 21,43 & $72.137,6$ & 19,93 & $-5.438,4$ & $-1,50$ \\
Semak belukar/Tanah terbuka & $55.679,4$ & 15,38 & $55.375,9$ & 15,30 & $-303,5$ & $-0,08$ \\
Sungai & $2.275,9$ & 0,63 & $2.275,9$ & 0,63 & - & - \\
Taman Bunga Nusantara & 24,0 & 0,01 & 24,0 & 0,01 & - & - \\
\hline Total & $361.944,3$ & 100,00 & $361.944,3$ & 100,00 & & \\
\hline
\end{tabular}

Sumber : Hasil olahan citra satelit

Penggunaan lahan hutan paling banyak beralih fungsi menjadi kebun/kebun campuran, yaitu sebesar 3,144 ha dan paling tinggi terjadi di Kecamatan Campakamulya, yaitu seluas 573 ha. Hal ini karena secara umum lokasi desadesa di Kecamatan Campakamulya berada di tepi atau sekitar kawasan hutan. Selain itu, pertanian di kecamatan ini didominasi oleh palawija sehingga sejalan dengan fakta bahwa penurunan luas hutan diikuti dengan penambahan kebun/kebun campuran.

Penggunaan lahan ladang berubah paling banyak menjadi kebun/kebun campuran, yaitu seluas 4,233 ha dengan perubahan tertinggi terdapat di kecamatan Campaka seluas 1,140 ha. Sementara itu penggunaan lahan kebun/kebun campuran berubah paling banyak menjadi pemukiman di Kecamatan Cibeber, yaitu seluas 139 ha. Ladang berubah paling banyak di Kecamatan Cikadu, seluas $1,895.1$ ha.

Penggunaan lahan sawah paling banyak beralih fungsi menjadi pemukiman sebesar 4,067 ha. Bentuk perubahan ini paling banyak terjadi di Kecamatan Pacet dan Sukaresmi masing-masing sebesar 416 ha dan 392 ha. Hal ini disebabkan kedua kecamataan tersebut tergolong ke dalam WP Cianjur bagian Utara dan merupakan bagian perkotaan Cipanas. Selain itu, pada Kecamatan Pacet hanya $30.47 \%$ keluarga yang bekerja disektor pertanian, sedangkan $69.53 \%$ lainnya tersebar diberbagai sektor nonpertanian. Perkembangan pemukiman yang pesat di kedua kecamatan ini disebabkan posisinya yang telah memasuki daerah wisata Taman Bunga Nusantara serta dekat dengan Kawasan Puncak yang merupakan salah satu objek rekreasi alam yang banyak digemari masyarakat, baik dari dalam maupun luar Kabupaten Cianjur.

Pesatnya area pemukiman di daerah Pacet dan Sukaresmi bukan disebabkan karena peningkatan jumlah penduduk, tetapi karena banyaknya spekulasi masyarakat kota untuk menjadikan daerah ini sebagai tempat tinggal alternatif diluar tempat tinggal tetapnya. Tempat tinggal alternatif ini biasanya digunakan hanya pada saat libur akhir pekan sebagai rekreasi karena keindahan alam dan udara yang masih segar dibandingkan dengan daerah perkotaan. Akibatnya, pembangunan villa, restoran, dan perumahan di daerah ini menyebabkan luas dan proporsi pemukiman meningkat karena nilai economic land rent-nya yang tinggi. Lahan sawah sendiri cenderung terus terkonversi karena memiliki nilai economic land rent yang lebih rendah.

Konversi sawah umumnya dimulai dengan merubah lahan sawah menjadi lahan kering dan kemudian menjadi lahan non-pertanian. Hal seperti ini banyak dilakukan secara sengaja untuk memberikan kesan seakanakan tidak menyalahi peraturan perundangan yang berlaku. Hasil penelitian menunjukkan bahwa transisi perubahan 
dari ladang menjadi kebun/kebun campuran dan selanjutnya kebun/kebun campuran menjadi pemukiman merupakan hal yang perlu menjadi perhatian pemerintah setempat.

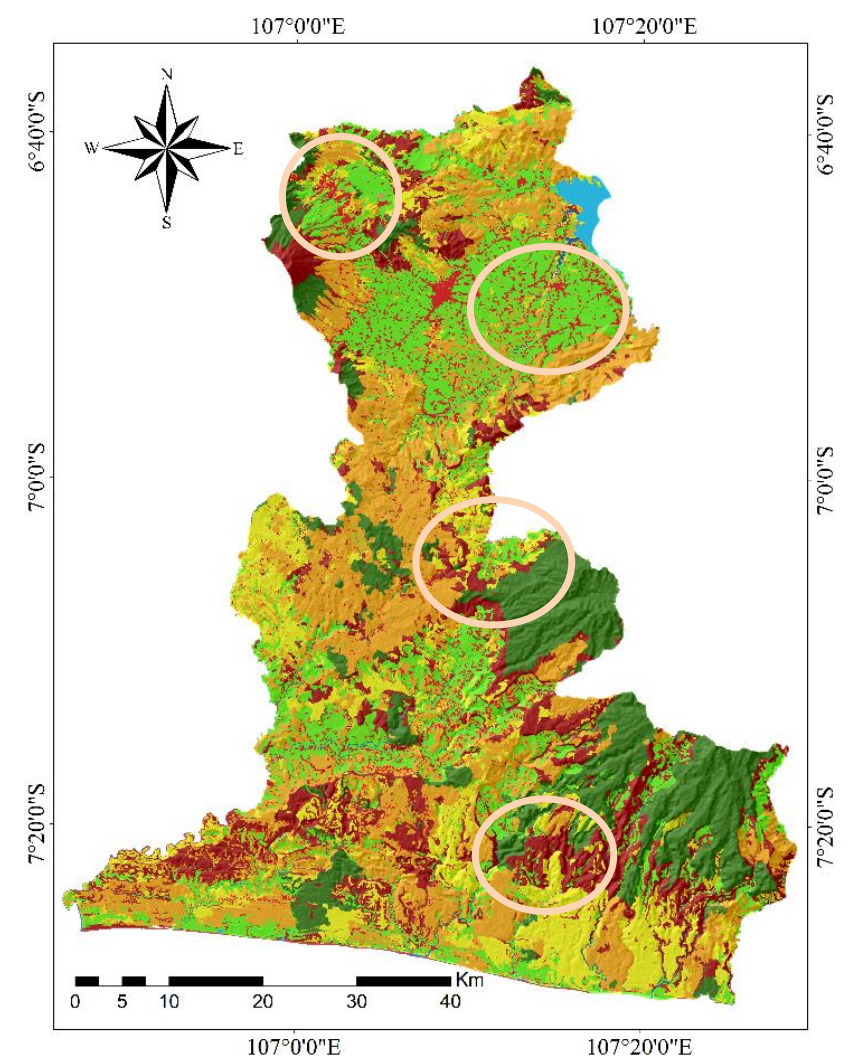

(a)
Peta penggunaan lahan tahun 2000 dan 2015 disajikan pada Gambar 1a dan $1 \mathrm{~b}$.

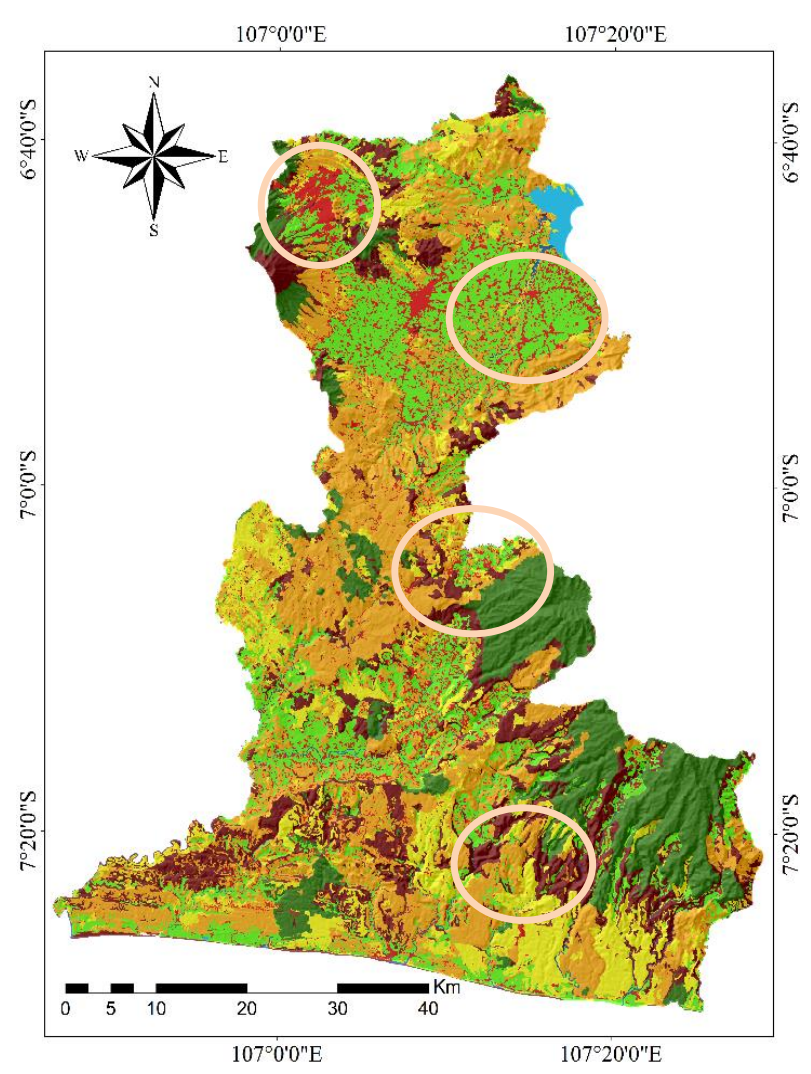

(b)

Keterangan :

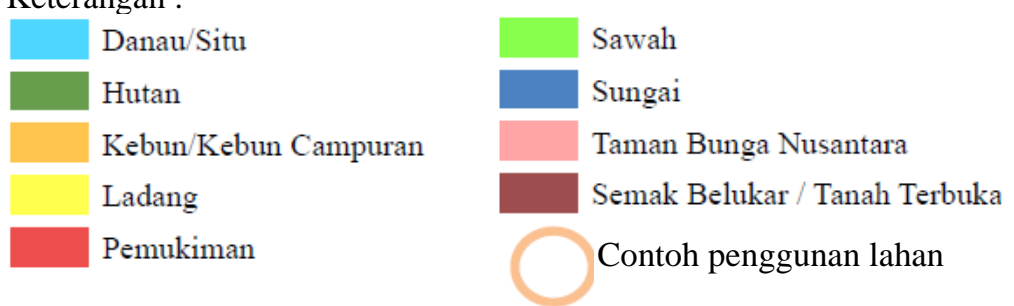

Gambar 1. Peta penggunaan lahan Kabupaten Cianjur (a) tahun 2000 (b) tahun 2015

\section{Pola Spasial Konversi Sawah Kabupaten Cianjur}

Konversi sawah terlihat secara visual dari berkurangnya lahan sawah. Laju konversi sawah Kabupaten Cianjur dalam periode 2000-2015 sebesar $1.5 \%$ atau pengurangan lahan sawah seluas 5,438.4 ha. Lahan sawah di lokasi penelitian beralih fungsi menjadi pemukiman (66.98\%), ladang (11.01\%), kebun/kebun campuran $(19.20 \%)$, serta semak belukar/tanah terbuka (2.82\%). Peta konversi lahan sawah disajikan pada Gambar 2.

Karakteristik suatu lahan juga dapat digunakan untuk menggambarkan pola spasial keberadaan maupun konversi sawah. Karakteristik lahan yang digunakan dalam penelitian ini adalah kemiringan lereng, elevasi, dan jarak dari jalan. Hasil penelitian ini menunjukkan bahwa konversi lahan sawah dominan berada pada lereng datar (0-8\%) (Gambar 3). Hal ini sejalan dengan penelitian Iqbal dan Sumaryanto (2007) yang menyebutkan bahwa pembangunan prasarana dan sarana pemukiman, kawasan industri, dan sebagainya cenderung berlangsung cepat di wilayah bertopografi datar. Keberadaan sawah yang dominan berada di daerah datar dengan infrastruktur wilayah yang umumnya berkembang dengan baik menyebabkan lahan sawah pada topografi datar selalu menjadi target dalam pengembangan lahan terbangun.

Ditinjau dari aspek elevasi, konversi sawah paling banyak terjadi pada ketinggian 0-500 m dpl yang didominasi oleh perubahan sawah menjadi kebun/kebun campuran dan pemukiman. Perubahan sawah menjadi kebun/kebun campuran paling banyak terjadi di Kecamatan Agrabinta.

Sementara itu, perubahan sawah menjadi pemukiman paling banyak terjadi di Kecamatan Karangtengah. Hal ini disebabkan karena Kecamatan Karangtengah berbatasan langsung dengan Kecamatan Cianjur dimana terdapat Kota Cianjur yang merupakan pusat pemerintahan. Selain itu, Kota Cianjur memiliki sarana dan prasarana yang lebih lengkap dan merupakan jalur strategis karena dilewati oleh jalan utama yang menghubungkannya dengan Kabupaten Bogor di sebelah 
utara, Kabupaten Bandung di sebelah timur, Kabupaten Sukabumi di sebelah barat dan Kabupaten Purwakarta di sebelah selatan. Oleh karena itu ada kecenderungan masyarakat untuk mendirikan pemukiman atau bertempat tinggal di wilayah ini. Kecamatan Karangtengah sendiri merupakan kecamatan dengan jumlah penduduk terbesar kedua setelah Cianjur.

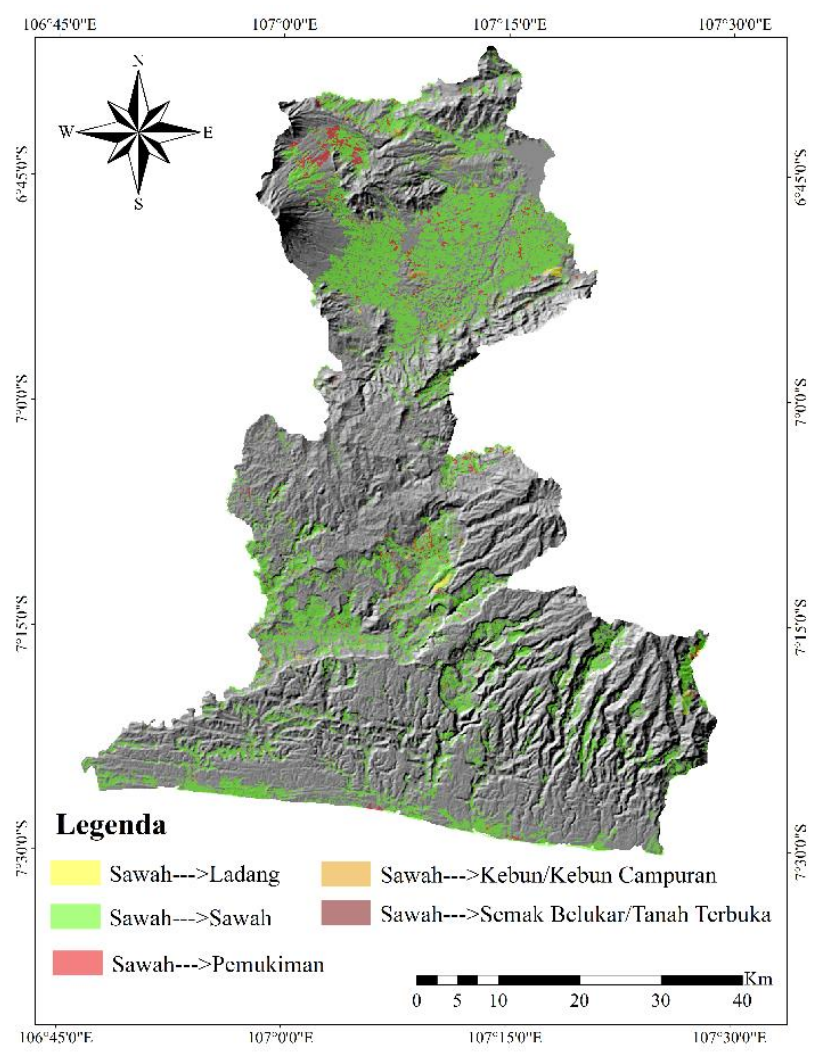

Gambar 2. Peta konversi lahan sawah Kabupaten Cianjur tahun $2000-2015$

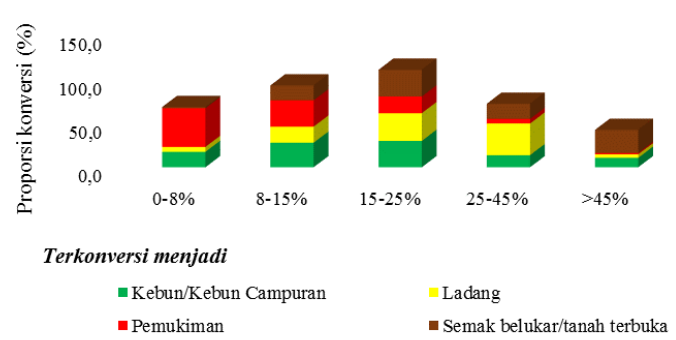

Gambar 3. Pola konversi sawah di Kabupaten Cianjur ditinjau dari kemiringan lereng

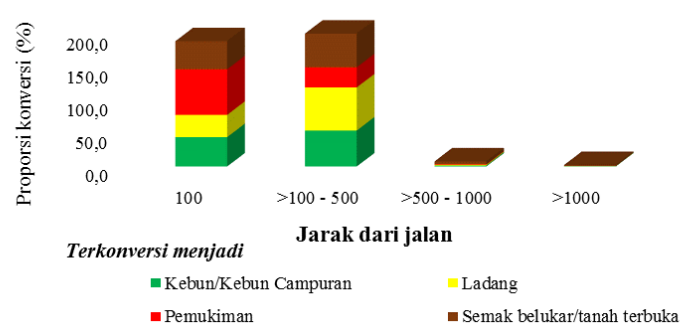

Gambar 4. Pola konversi sawah di Kabupaten Cianjur ditinjau dari elevasi

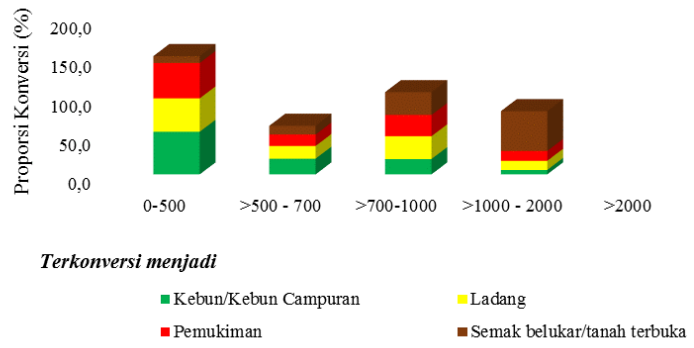

Gambar 5. Pola konversi sawah ditinjau dari jarak dari jalan

Ditinjau dari aspek kedekatan dengan jalan, secara teoritis pengembangan infrastruktur jalan akan diikuti oleh perkembangan wilayah (Rustiadi et al., 2010). Pengamatan terhadap pola hubungan sawah dengan jalan di Cianjur ini menunjukkan bahwa secara umum konversi lahan sawah dominan terjadi di dekat jalan dan cenderung menurun seiring dengan semakin jauhnya jarak dari jalan. Hal ini karena jarak dari jalan menggambarkan tingkat kemudahan mencapai sawah dari jalan yang ada (Widiatmaka et al., 2014). Penelitian Widiatmaka et al. (2013) di Kabupaten Karawang menyebutkan bahwa dalam hal konversi di wilayah itu, pengaruh jalan hanya sampai sejauh $1 \mathrm{~km}$ dari jalan. Pada jarak lebih dari $1 \mathrm{~km}$, pengaruh jalan tidak signifikan lagi. Konversi sawah ke pemukiman pada penelitian ini paling banyak terjadi pada jarak $100 \mathrm{~m}$.

\section{Kesesuaian Lahan untuk Sawah Kabupaten Cianjur}

Hasil penelitian menunjukkan bahwa sawah di Kabupaten Cianjur tersebar dalam 3 kelas kesesuaian untuk sawah, yaitu S2 (sesuai) seluas 34,496 ha (9.53\%), S3 (sesuai marjinal) seluas 105,966 ha $(29,28 \%)$, dan N (tidak sesuai) seluas 221,482 ha $(61.19 \%)$. Sebaran spasial titik pengambilan contoh tanah, kesesuaian sawah, dan faktor pembatas disajikan pada Gambar 6a, 6b dan Tabel 3.

Faktor pembatas utama pada lahan dengan kelas kesesuaian lahan $\mathrm{N}$ dan $\mathrm{S} 3$ adalah lereng, masing-masing sebesar 218,576.4 ha (98.69\%) dan 33,639.5 ha (31.75\%). Untuk kelas kesesuaian S2, faktor pembatas utamanya adalah tekstur dan kadar N-total seluas 7,840.3 ha (22.73\%). Dalam hal lereng, pengamatan di lapang menunjukkan bahwa pada lereng-lereng curam yang dipergunakan untuk sawah, umumnya telah dibuat terasering sehingga meskipun lerengnya secara makro relatif miring, namun secara mikro lahan menjadi datar dan sesuai untuk sawah. Erosi yang terjadi relatif kecil, hal ini juga memudahkan dalam pengelolaan. Faktor pembatas kadar N-total dapat diatasi melalui pemberian pupuk dengan cara aplikasi yang tepat. Untuk faktor pembatas tekstur, meskipun secara konseptual tekstur tanah tidak dapat dirubah, namun hal ini dapat dikompensasi melalui perbaikan struktur tanah dengan pemberian bahan organik. 


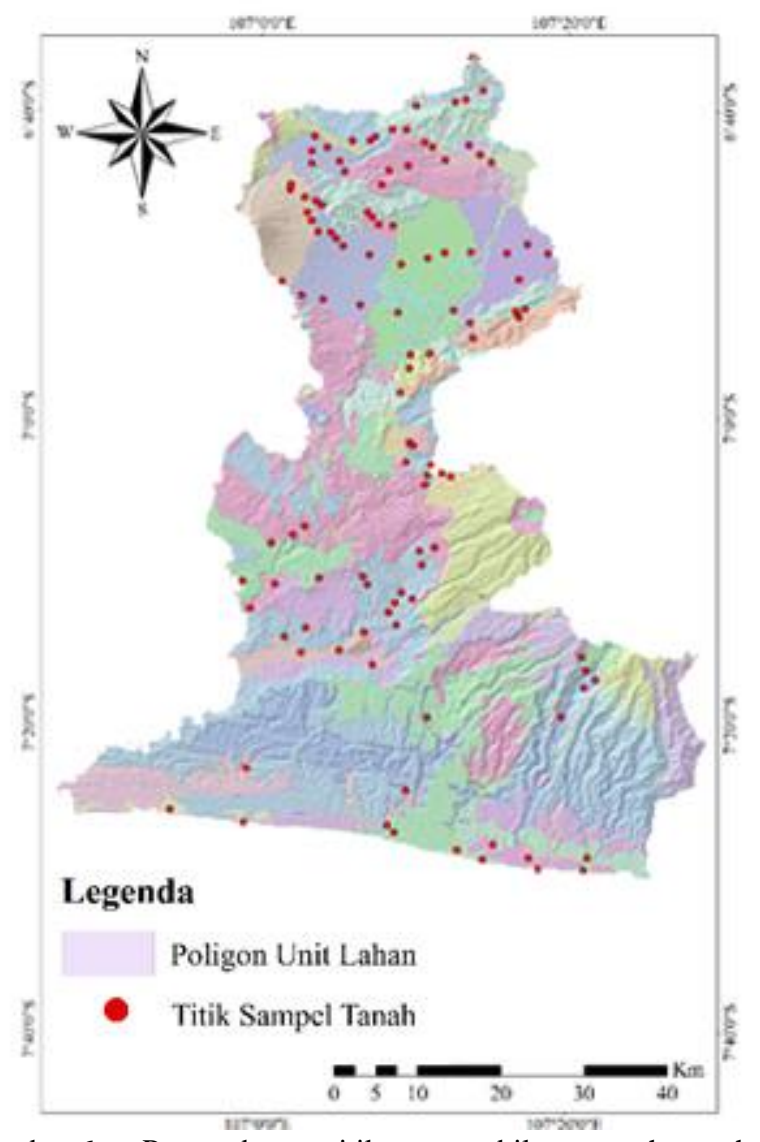

Gambar 6a. Peta sebaran titik pengambilan contoh tanah di Kabupaten Cianjur

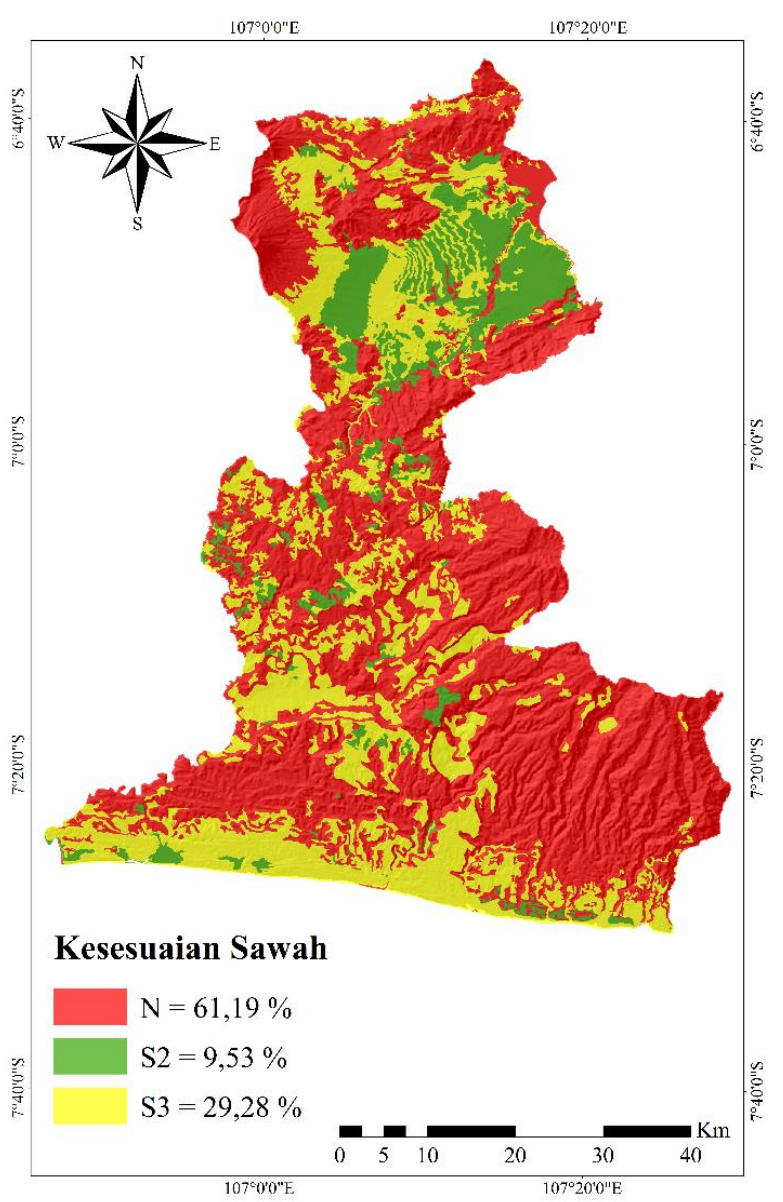

Gambar 6b. Peta Peta kesesuaian lahan sawah di Kabupaten Cianjur
Tabel 3. Faktor hambat pada setiap kelas kesesuaian sawah

\begin{tabular}{|c|c|c|c|}
\hline Kesesuaian & Karakteristik & Komponen & $\begin{array}{r}\text { Luas } \\
\text { (ha) }\end{array}$ \\
\hline \multirow{12}{*}{$\mathrm{N}$} & $\mathrm{Ne}$ & Lereng & 218576,4 \\
\hline & $\mathrm{Nr}$ & Tekstur & 40,5 \\
\hline & & Lereng dan $\mathrm{pH}$ & 3843,9 \\
\hline & S2ef & Lereng, $\mathrm{Kb}$, dan $\mathrm{pH}$ & 12,4 \\
\hline & & Lereng, Ktk, Kb, dan $\mathrm{pH}$ & 73,5 \\
\hline & S2en & Lereng dan Ntot & 8,8 \\
\hline & & $\mathrm{Kb}$ dan C-organik & 56,1 \\
\hline & S2f & $\mathrm{Ktk}, \mathrm{Kb}$, dan $\mathrm{pH}$ & 1494,4 \\
\hline & & $\mathrm{pH}$ & 872,5 \\
\hline & S2fn & C-organik dan Ntot & 919,7 \\
\hline & S2n & Ntot & 144,4 \\
\hline & S2r & Tekstur & 877,4 \\
\hline \multirow[t]{21}{*}{ S2 } & S2re & Tekstur dan Lereng & 207,8 \\
\hline & S2ref & Tekstur, Lereng, dan C-organik & 331,2 \\
\hline & & Tekstur, Lereng, dan $\mathrm{pH}$ & 19,8 \\
\hline & S2refn & Tekstur, Lereng, C-organik, dan Ntot & 3230,6 \\
\hline & & Tekstur dan C-organik & 6552,6 \\
\hline & S2rf & Tekstur dan $\mathrm{pH}$ & 1227,9 \\
\hline & & Tekstur, C-organik, dan Ntot & 4767,5 \\
\hline & & Tekstur, Ktk, pH, C-organik, dan Ntot & 1044,5 \\
\hline & S2rtn & Tekstur, pH, C-organik, dan Ntot & 520,5 \\
\hline & & Tesktur, $\mathrm{pH}$, dan Ntot & 450,5 \\
\hline & S2rn & Tekstur dan Ntot & 7840,3 \\
\hline & S3ef & Lereng dan C-organik & 2,2 \\
\hline & S3efn & Drainase dan Ntot & 1353,7 \\
\hline & S3en & Lereng dan Ntot & 6339,8 \\
\hline & S3f & C-organik & 2690,7 \\
\hline & S3n & Ntot & 6566,0 \\
\hline & & Drainase & 9600,9 \\
\hline & $\mathrm{S} 3 \mathrm{r}$ & Drainase dan Kedalaman efektif & 29,4 \\
\hline & & Kedalaman efektif & 7679,3 \\
\hline & & Drainase dan Lereng & 18901,3 \\
\hline & S3re & Kedalaman efektif dan Lereng & 66,4 \\
\hline \multirow[t]{12}{*}{ s3 } & & Drainase, Lereng, dan C-organik & 63,9 \\
\hline & S3ref & Drainase, Lereng, dan $\mathrm{Kb}$ & 7,5 \\
\hline & S3ref & Drainase, Lereng, C-organik, dan Ntot & 41,4 \\
\hline & 3 reern & Tekstur, Lereng, C-organik, dan Ntot & 546,5 \\
\hline & S3ren & Drainase, Lereng, dan Ntot & 12156,9 \\
\hline & Soren & Drainase, Lereng, Kedalaman efektif, dan Ntot & 367,2 \\
\hline & S3rf & Drainase dan C-organik & 924,1 \\
\hline & & Drainase, C-organik, dan Ntot & 336,8 \\
\hline & $3 . \mathrm{rm}$ & Drainase, Lereng, C-organik, dan Ntot & 270,1 \\
\hline & & Drainase dan Ntot & 1988,7 \\
\hline & S3rn & Drainase, Kedalaman efektif, dan Ntot & 349,3 \\
\hline & & Kedalaman efektif dan Ntot & 2044,7 \\
\hline
\end{tabular}

\section{Potensi Lahan untuk Perluasan Sawah}

Berdasarkan penggunaan lahan eksisting hasil interpretasi citra tahun 2015, lahan yang berpotensi untuk dialokasikan menjadi sawah adalah penggunaan lahan pertanian non-sawah (ladang dan kebun/kebun campuran) dan lahan tidak produktif (semak belukar/tanah terbuka) (Gambar 7). Hal ini kemudian diintegrasikan dengan ketersediaan lahan pertanian berdasarkan RTRW Kabupaten Cianjur (Tabel 4).

Hasil integrasi ini menunjukkan bahwa di Kabupaten Cianjur masih terdapat 148,980 ha lahan yang berpotensi untuk dijadikan sawah. Berdasarkan pemrioritasan, luas lahan potensial untuk disawahkan pada prioritas pertama (P1) adalah seluas 188 ha, pada prioritas kedua (P2) seluas 5,470 ha, pada prioritas ketiga (P3) seluas 58,350 ha dan pada prioritas keempat $(\mathrm{P} 4)$ seluas 84,971 ha.

\section{SIMPULAN}

Pada periode 2000-2015, penggunaan/penutupan lahan hutan, ladang, sawah, dan semak belukar/tanah terbuka mengalami penurunan sedangkan pemukiman dan kebun/kebun campuran mengalami peningkatan. Selama periode tersebut, keberadaan lahan sawah semakin tertekan. Lahan sawah berkurang seluas 5,438.4 ha dengan dominansi perubahan menjadi pemukiman, yaitu sebesar $66.98 \%$ dari perubahan keseluruhan. Wilayah Kabupaten Cianjur memiliki tingkat kesesuaian lahan untuk sawah 
berkisar dari S2, S3 sampai N. Faktor pembatas utama untuk kelas kesesuaian lahan $\mathrm{N}$ dan S3 adalah lereng, sedangkan faktor pembatas utama untuk lahan kelas S2 adalah tekstur dan N-total.

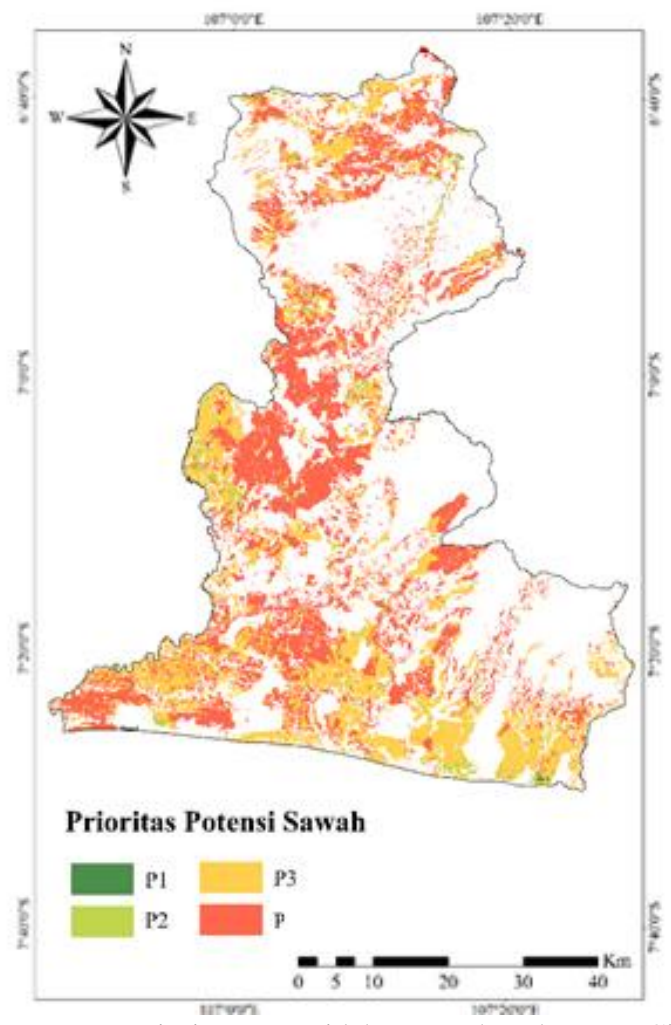

Gambar 7. Peta prioritas potensi lahan sawah Kabupaten Cianjur

Tabel 4. penetapan potensi lahan untuk pengalokasian sawah

\begin{tabular}{|c|c|c|c|}
\hline Landuse 2015 & $\begin{array}{c}\text { Kesesuaian } \\
\text { Sawah }\end{array}$ & RTRW & Prioritas \\
\hline \multirow{4}{*}{ Ladang, Semak belukar/Tanah terbuka } & $\mathrm{S} 2$ & \multirow{2}{*}{ Pertanian lahan basah, Sempadan sungai } & P1 \\
\hline & S3 & & $\mathrm{P} 2$ \\
\hline & S2 & \multirow{2}{*}{ Pertanian lahan kering } & $\mathrm{P} 2$ \\
\hline & S3 & & $\mathrm{P} 3$ \\
\hline Ladang & S2, S3 & Perkebunan/Tanaman tahunan & P3 \\
\hline Semak belukar/Tanah terbuka & S2,S3 & Perkebunan/Tanaman tahunan & $\mathrm{P} 4$ \\
\hline \multirow{5}{*}{ Kebun/kebun campuran } & S2 & \multirow{2}{*}{ Pertanian lahan basah, Sempadan sungai } & $\mathrm{P} 2$ \\
\hline & S3 & & $\mathrm{P} 3$ \\
\hline & $\mathrm{S} 2, \mathrm{~S} 3$ & Perkebunan/Tanaman tahunan & $\mathrm{P} 4$ \\
\hline & S2 & \multirow{2}{*}{ Pertanian lahan kering } & $\mathrm{P} 2$ \\
\hline & S3 & & P3 \\
\hline
\end{tabular}

Penelitian yang dilakukan juga memperlihatkan besarnya tingkat konversi lahan sawah. Oleh karena itu, disarankan pemerintah Kabupaten Cianjur segera melakukan penetapan perlindungan bagi lahan yang memiliki potensi yang baik (terutama pada lahan dengan prioritas 1 dan 2) untuk dijadikan sawah. Selain itu, pengadaan alat-alat pertanian juga perlu diperhatikan untuk mendukung kelangsungan produksi. Berdasarkan integrasi kelas kesesuaian dan alokasi lahan pada RTRW, Kabupaten Cianjur masih memiliki potensi lahan untuk dijadikan sawah seluas 148,980 ha.

\section{DAFTAR PUSTAKA}

[BPS] Badan Pusat Statistik Kabupten Cianjur. 2003. Kabupaten Cianjur Dalam Angka Tahun 2003. BPS Kabupaten Cianjur, Cianjur.
[BPS] Badan Pusat Statistik Kabupten Cianjur. 2014. Kabupaten Cianjur Dalam Angka Tahun 2014. BPS Kabupaten Cianjur, Cianjur.

[BPS] Badan Pusat Statistik Provinsi Jawa Barat. 2014. Provinsi Jawa Barat Dalam Angka Tahun 2014. BPS Provinsi Jawa Barat, Bandung.

Badan Litbang Pertanian. 2011. Konversi dan Fragmentasi Lahan Ancaman Terhadap Kemandirian Pangan. Editor. Pasandaran E., Kasryno F., Saliem H.P., Soeparno H., Pasaribu S.M. Kampus IPB Taman Kencana Bogor, Jakarta.

Belesky, P. 2014. Regional governance, food security and rice reserves in East Asia. J. Global Food Security., 3:167-173.

Borrelli, P., S. Modugno., P. Panagos., M. Marchetti., B. Schutt and L. Montanarella. 2014. Detection of harvested forest areas in Italy using landsat imagery. J. Applied Geography, 48:102-111.

Cahyaningrum, W., Widiatmaka dan K. Soewardi. 2014. Arahan spasial pengembangan mina padi berbasis kesesuaian lahan dan analisis A'WOT di Kabupaten Cianjur, Jawa Barat. Globe, 16 (1): 77-88.

Cornish, P.S., D. Karmakar., A. Kumar., S. Das and B. Croke. 2015. Improving crop production for food security and improved livelihoods on the East India Plateau. I. Rainfall-related risk with rice and opportunities for improved cropping systems. $J$. Agricult. Systems, 137:166-179.

Hardjowigeno, S. dan Widitamaka. 2007. Evaluasi Kesesuaiaan Lahan dan Perencanaan Tataguna Lahan. UGM Univ Pr., Bogor.

Kim, D.H., J.O. Sexton., P. Noojipady., C. Huang., A. Anand., S. Channan., M. Feng and J.R. Townshend. 2014. Global, landsat-based forest-cover change from 1990 to 2000. J. Remote Sens. of Environment, 155:178-193.

Kolios, S. and C.D. Stylios. 2013. Identification of land cover/land use changes in the greater area of the Preveza peninsula in Greece using landsat satellite data. J. Applied Geography, 40:150-160.

Munibah, K. dan G. Komarsa. 2015. Daya Dukung Lahan Sawah dan Kemandirian Pangan Domestik di Kabupaten Cianjur. Laporan tahunan penelitian strategis, Bogor.

[PUSDATIN KEMENTAN] Pusat Data dan Informasi Kementerian Pertanian. 2014. Peta Penggunaan Lahan Tahun 1990-2014. Pusdatin Kementan RI, Jakarta

Qiu, B., W. Li., Z. Tang., C. Chen and W. Qi. 2015. Mapping paddy rice areas based on vegetation phenology and surface moisture conditions. $J$. Ecological Indicators, 56:97-86.

Rustiadi E. dan R. Wafda. 2008. Urgensi pengembangan lahan pertanian pangan abadi dalam perspektif ketahanan pangan. In A. Sitanala. Dan R. Ernan 
(Ed.). Penyelamatan Tanah, Air dan Lingkungan. Crestpent, Yayasan Obor Indonesia, Jakarta.

Rustiadi, E., B. Barus dan M. Selari. 2010. Kebijakan Lahan Pertanian Pangan Berkelanjutan dan Penataan Ruang. Makalah Seminar pada Semiloka Koordinasi Kebijakan Pengelolaan Dan Penyediaan Lahan Untuk Pertanian; 2010 Apr 14; Bogor, Indonesia. Dilaksanakan oleh Menko Perekonomian dan P4WIPB, Bogor.

Suhaema, E., Widiatmaka dan B. Tjahjono. 2014. Pengembangan wilayah peternakan sapi potong berbasis kesesuaian fisik lingkungan dan kesesuaian lahan untuk pakan di Kabupaten Cianjur. Jurnal Tanah dan Lingkungan, 16: 53-60.

Widiatmaka, W. Ambarwulan and K. Munibah. 2013. Landuse Change During A Decade As Determined By Landsat Imagery of A Rice Production Region And Its Implication To Regional Contribution To Rice Self Sufficiency : Case Study Of Karawang Regency, West Java, Indonesia. In Pramono GH, D.
Ramdani, B. Barus and R.M. Ariansyah (Eds.). Proceedings of the 34th Asian Conference on Remote Sensing. The festive of science, education, nation, and culture. Bali, Indonesia. Masyarakat Ahli Penginderaan Jarak Jauh (MAPIN). Bogor. Hal. 126-132.

Widiatmaka, W. Ambarwulan, K., K. Munibah dan B.K. Santoso Paulus. 2013. Analisis perubahan penggunaan lahan dan kesesuaian lahan untuk sawah di sepanjang jalur jalan tol Jakarta-Cikampek dan jalan nasional pantura, Kab.Karawang. Seminar Nasional dan Forum Ilmiah Tahunan Ikatan Surveyor Indonesia (FIT ISI): Peran geospasial dalam pengelolaan sumber daya agraria secara berkelanjutan. Sekolah Tinggi Pertanahan Nasional, Yogyakarta.

Yang, D. and M. Zhang. 2014. Effects of land-use conversion from paddy field to orchard farm on soil microbial genetic diversity and community structure. European J. of Soil Biology, 64:30-39. 